\title{
Verhandlungen der Moskauer venerologischen und dermatologischen Gesellschaft.
}

\author{
Sitzung vom 9. April (27. März) 1911.
}

1. Fokin zeigte eine 25jährige Frau mit hämorrhagischem makulösen Exanthem an rechter Hälfte des Rumpfes und am rechten Oberschenkel. Die Krankheit dauert 1 Jahr und darf vielleicht als Folge eines Stoßes in der Rückengegend erklärt werden.

Bogrow und Krasnoglas ow möchten auf Grund der zosterähnlichen Anordnung der Eruption in dem Falle trophische Hautveränderung als Folge einer Verletzung des Rückenmarks sehen.

2. Bogrow stellte zum zweiten_Male (s. Krankendemonstration in der Moskauer dermatologischen Klinik am 19./6. Februar d. J.) die Kranke mit Granuloma fungoides und Parakeratosis variegata vor. Nach intravenöser Einspritzung des Salvarsans (0.6) Temperatursteigerung, lokale Reaktion des Ausschlages und dessen partielle Resorption. Aber die Besserung dauerte nur kurze Zeit und endlich wurde mit Röntgenbehandlung angefangen.

Krasnoglasow hat auch in seinem Falle nur vorübergehende Besserung nach Salvarsan gesehen.

3. Muchin demonstrierte ein 16jähriges Mädchen mit Sclerodermie en bandes und en plaques. An einigen Stellen beginnende Atrophie. Wassermann negativ. Salvarsanbehandlung ohne Erfolg.

4. Muchin stellte zum zweiten Male (s. ibidem) die Kranke mit Dermatitis herpetiformis Dühringi vor. An Stelle einiger Flecken entstanden Milia. Die Zungenschleimhaut ist leicht atrophisch geworden. Mit den Menses werden die erythematösen Girlanden deutlicher. Nach Adrenalintherapie (10 Tropfen 3mal täglich) sind die Blasen viel seltener. Der Fall bietet einen Übergang zur dystrophischen Form der Epidermolysis bullosa dar.

5. Metscherski zeigte ein 17jähriges Mädchen, das seit 8 Jahren an Syphilis gummosa ulcerosa des Vorderarmes litt. Jetzt sind alle Weichteile und Knochen atrophisch, dadurch ist die Extremität unbrauchbar geworden.

6. Tschernogubow teilte mit seine Beobachtungen über Salvars ananwendung bei Syphilis: die intravenöse Applikation muB vorgezogen werden, aber sogar nach ihr ist das Negativwerden der Wasserm a n nschen Realktion eher eine Ausnahme. Andere Krankheitssymptome verschwinden rasch. Zum Schluß muß doch eine kombinierte (Salvarsan + Quecksilber) Behandlung empfohlen werden. 
548 Verhandlungen der Moskauer ven. und dermat. Gesellschaft.

Metscherski sieht einen großen sozialen Wert der Salvarsanbehandlung in rascher Beseitigung der Schleimhautpapeln. Le wtschen skow erklärt das Frösteln nach intravenösen Einspritzungen durch ungenügend warme Lösung. Bogrow sah bei einem Syphilitischen mit Lungenspitzenaffektion lokale Reaktion des Herdes nach intravenöser Einspritaung des Salvarsans. Tschernogubow beobachtete bei einem Tuberkulösen (mit Bazillen) vorübergehende Pleuritis nach Salvarsaninjektion (intravenös). Krasnoglasow konnte keine ungünstige Wirkung des Salvarsans (Emulsion) bei einer tuberkulösen Frau beobachten.

7. Bogrow demonstrierte den Apparat von Prof. Bobroff für intravenöse Einspritzungen in seiner Modifikation.

Tschernogubow zieht seine eigene Modifikation vor. Bogda now und Braunstein arbeiten mit einer Modifikation des Apparates von Assmy.

8. Lewtschenkow zeigte Photographie eines Falles mit 13 Ulc. indurata.

Krasnoglasow hat bis jetzt nur einen Fall mit 10 Primäraffekten gesehen.

9. Bogrow zeigte Abbildungen der primären Diphtherie der W angenha ut bei einer Mutter, die ihr krankes Kind stillte. Heilung nach Anwendung von antidiphtherischem Serum in einigen Tagen.

Priv.-Doz. S. Bog row (Moskan). 